Louisiana State University

LSU Digital Commons

Faculty Publications

Department of Chemistry

$1-1-2007$

\title{
Poly[di(2-thiophenyl)carborane]s: Conducting polymers with high electrochemical and thermal resistance
}

\author{
Erhong HaO \\ Louisiana State University \\ Bruno Fabre \\ Institut des Sciences Chimiques de Rennes \\ Frank R. Fronczek \\ Louisiana State University \\ M. Graça H. Vicente \\ Louisiana State University
}

Follow this and additional works at: https://digitalcommons.Isu.edu/chemistry_pubs

\section{Recommended Citation}

Hao, E., Fabre, B., Fronczek, F., \& Vicente, M. (2007). Poly[di(2-thiophenyl)carborane]s: Conducting polymers with high electrochemical and thermal resistance. Chemical Communications (42), 4387-4389. https://doi.org/10.1039/b710375a

This Article is brought to you for free and open access by the Department of Chemistry at LSU Digital Commons. It has been accepted for inclusion in Faculty Publications by an authorized administrator of LSU Digital Commons.

For more information, please contact ir@lsu.edu. 


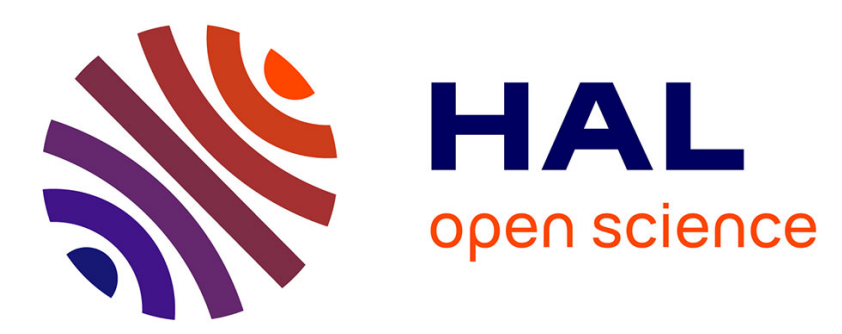

\title{
Poly[di(2-thiophenyl)carborane]s: conducting polymers with high electrochemical and thermal resistance.
}

\author{
Erhong Hao, Bruno Fabre, Frank R. Fronczek, M. Graça H. Vicente
}

\section{To cite this version:}

Erhong Hao, Bruno Fabre, Frank R. Fronczek, M. Graça H. Vicente. Poly[di(2-thiophenyl)carborane]s: conducting polymers with high electrochemical and thermal resistance.. Chemical Communications, Royal Society of Chemistry, 2007, pp.4387-9. 10.1039/b710375a . hal-00189188

\section{HAL Id: hal-00189188 \\ https://hal.archives-ouvertes.fr/hal-00189188}

Submitted on 23 Aug 2013

HAL is a multi-disciplinary open access archive for the deposit and dissemination of scientific research documents, whether they are published or not. The documents may come from teaching and research institutions in France or abroad, or from public or private research centers.
L'archive ouverte pluridisciplinaire HAL, est destinée au dépôt et à la diffusion de documents scientifiques de niveau recherche, publiés ou non, émanant des établissements d'enseignement et de recherche français ou étrangers, des laboratoires publics ou privés. 


\title{
Poly[di(2-thiophenyl)carborane]s: conducting polymers with high electrochemical and thermal resistance $\dagger \dagger$
}

\author{
Erhong Hao, ${ }^{a}$ Bruno Fabre, $^{* b}$ Frank R. Fronczek ${ }^{a}$ and M. Graça H. Vicente* \\ Received (in Cambridge, UK) 9th July 2007, Accepted 7th August 2007 \\ First published as an Advance Article on the web 16th August 2007 \\ DOI: $10.1039 / b 710375 a$
}

The synthesis, X-ray structure and electropolymerization of three new carbon-carbon linked di(2-thiophenyl)carboranes (1o, $1 \mathrm{~m}$ and $1 \mathrm{p})$ are reported; the resulting polymers bearing icosahedral ortho-, meta- or para-carborane clusters show high thermal and electrochemical stabilities in comparison with unsubstituted polythiophene; the ortho-carborane-containing polymer has the highest conductivity of the new materials.

Conjugated organic polymers, such as polythiophenes, are promising semiconducting materials with applications in sensory signal amplification, and in microelectronics, optoelectronics and electromechanical devices. ${ }^{1-4}$ Therefore, the development of conducting organic polymers of high chemical and thermal stabilities is currently an active area of research. ${ }^{5-8}$ In particular the introduction of bulky hydrophobic groups into the polymer backbone has been investigated as a means to improve the stability and performance of the polymers. ${ }^{9}$ The icosahedral carborane clusters $o$-, $m$ - and $p-\mathrm{C}_{2} \mathrm{~B}_{10} \mathrm{H}_{12}$ are attractive substituents as they are well-known for their electron-deficient nature, large molecular volume, high hydrophobicity, and high electrochemical and thermal stabilities. For example it has been shown that poly(carborane-siloxane)s have increased chemical and thermal stabilities compared with the unsubstituted parent polymers, ${ }^{10-12}$ and that the introduction of the cobaltabisdicarbollide anion as doping anion, ${ }^{13,14}$ or covalently bonded carborane clusters, ${ }^{15,16}$ significantly improved the overoxidation threshold of the resulting polypyrroles. Herein we describe the synthesis and electropolymerization of three new carbon-carbon linked di(2-thiophenyl)carboranes (1o, 1m and 1p) to form polymers of high thermal and electrochemical stabilities. We anticipated that the three isomers bearing ortho-, meta- or para-carboranes, would produce polymers of defined geometry and conductivity.

$\operatorname{Di}(2$-thiophenyl)carboranes $\mathbf{1 o}, \mathbf{1 m}$ and $\mathbf{1 p}$, bearing respectively an ortho-, meta- or para-carborane group were synthesized from 2-iodothiophene as shown in Scheme 1. Compound 10 was obtained in two steps, via the reaction of di(2-thiophenyl)acetylene

${ }^{a}$ Department of Chemistry, Louisiana State University, Baton Rouge, LA, 70803, USA.E-mail: vicente@lsu.edu; Fax: 225-578-3458; Tel: $225-578-7405$

${ }^{b}$ Matière Condensée et Systèmes Electroactifs MaCSE, Sciences Chimiques de Rennes, Unité Mixte de Recherche $n^{\circ} 6226$ CNRS/ Université de Rennes 1, Campus de Beaulieu, 35042, Rennes Cedex, France. E-mail: bruno.fabre@univ-rennes1.fr; Fax: 33-22323-6732; Tel: $33-22323-6550$

$\uparrow$ The HTML version of this article has been enhanced with colour images.

t Electronic supplementary information (ESI) available: Synthetic procedures, electrochemistry, UV-visible spectroscopy and conductivity data. See DOI: $10.1039 / \mathrm{b} 710375 \mathrm{a}$ with decaborane, in $24 \%$ overall yield. On the other hand, compounds $1 \mathbf{m}$ and $1 \mathbf{p}$ were prepared in a single step in 36 and $39 \%$ yields, respectively, via the coupling reaction of 2-iodothiophene with the dilithium salt of either $m$ - or $p$-carborane, in the presence of cuprous iodide. ${ }^{17}$ The structures of the three di(2thiophenyl)carborane isomers were characterized by NMR, MS (see ESI ) and by X-ray crystallography, $\S$ as shown in Fig. 1. In all three structures, thiophenes exhibit the common disorder by twofold rotation about the thiophene-carborane $\mathrm{C}-\mathrm{C}$ bonds, swapping $\mathrm{S}$ and $\mathrm{C}$ positions. The $o$-isomer has two independent molecules, one having an ordered thiophene and a $56: 44$ disordered one, the other having an ordered thiophene and a 90 : 10 disordered one. The $m$-isomer has crystallographic $C_{2}$ symmetry, with the thiophene disordered $78: 22$. The $p$-isomer has crystallographic inversion symmetry, with thiophene disordered $75: 25$

All three compounds $\mathbf{1 0}, \mathbf{1 m}$ and $\mathbf{1 p}$ were readily oxidized electrochemically to form the corresponding polymer films, at oxidation potentials that increased in the order $10<\mathbf{1 m}<\mathbf{1 p}$ (Table 1). The lower oxidation potential required in the case of $\mathbf{1 0}$ made it more favorable in the electropolymerization process, by overcoming the so-called "polythiophene paradox" and achieving high conductivity. Typical cyclic voltammograms corresponding to the potentiodynamical electropolymerization of 10 are shown in Fig. 2. The electrochemical response of the electrogenerated polymers showed the same trend as that observed for the monomers, namely the formal potential decreasing in the order poly $(\mathbf{1 0})<\operatorname{poly}(\mathbf{1 m})<\operatorname{poly}(\mathbf{1 p})$. Among them, poly(10) shows the highest doping level (0.50) (Fig. 3), which is associated with the formation of largest population of bipolaron charge carriers. The generation of bipolaron charge carriers largely reduced the $\pi-\pi^{*}$
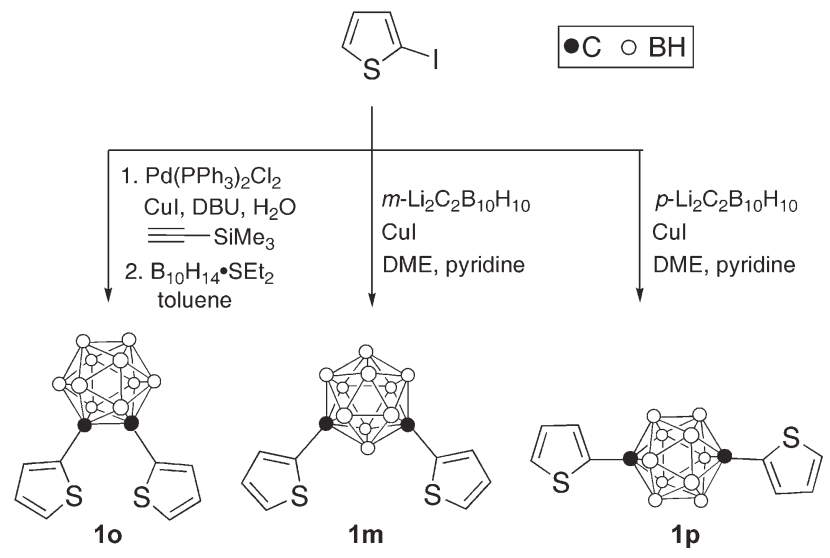

Scheme 1 Synthesis of di(2-thiophenyl)carboranes. 

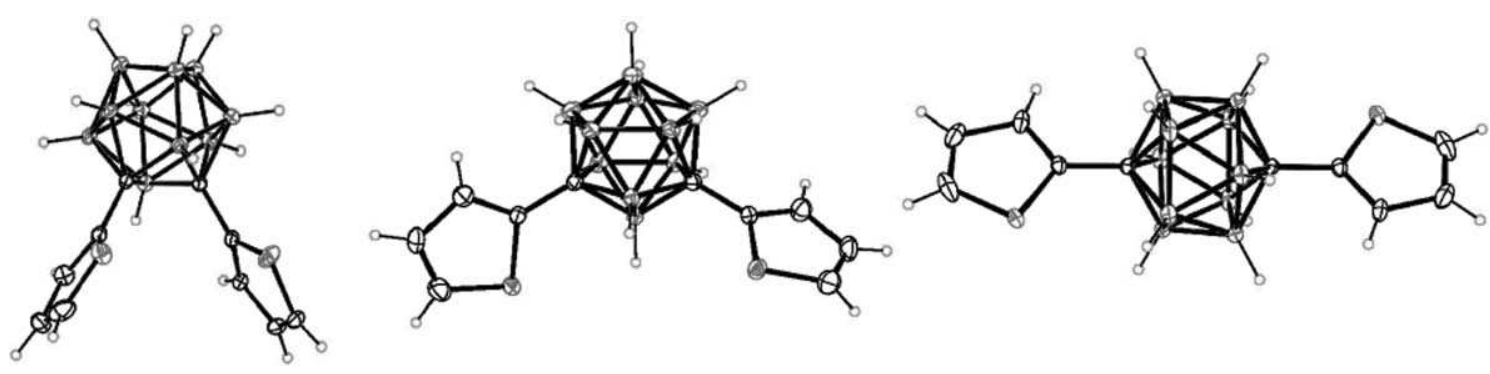

Fig. 1 X-Ray crystal structures of $\mathbf{1 o}, \mathbf{1 m}$ and $\mathbf{1 p}$, with $50 \%$ probability for the ellipsoids. Only the major conformer of each disordered thiophene is shown.

Table 1 Cyclic voltammetry data of $10,1 \mathrm{~m}$ and $1 \mathrm{p}$ at $10^{-2} \mathrm{M}$ in $\mathrm{CH}_{2} \mathrm{Cl}_{2}+2 \times 10^{-1} \mathrm{M} \mathrm{Bu}_{4} \mathrm{NPF}_{6}$. Potential scan rate: $0.1 \mathrm{~V} \mathrm{~s}^{-1}$

\begin{tabular}{lllll}
\hline & $E_{\text {pa mon }}{ }^{a} / \mathrm{V}$ & $E_{\text {poly }}^{\circ} / \mathrm{V}$ & $\delta^{c}$ & $\lambda_{\max }{ }^{d} / \mathrm{nm}$ \\
\hline $\mathbf{1 0}$ & $0.90 ; 1.70 ; 2.15$ & 0.52 & 0.50 & $528 ; 565 ; 615$ \\
$\mathbf{1 m}$ & $1.11 ; 1.84 ; 2.18$ & 0.87 & 0.07 & 488 \\
$\mathbf{1 p}$ & $1.12 ; 1.82 ; 2.06$ & 1.14 & 0.06 & 425
\end{tabular}

${ }^{a}$ Irreversible anodic peak potentials corresponding to the monomer oxidation. ${ }^{b}$ Formal potential corresponding to the reversible p-doping/undoping of the electrogenerated polythiophene (average of anodic and cathodic peak potentials). ${ }^{c}$ The doping level $\delta$ is the number of positive charge per monomer unit and has been calculated from the anodic charge $Q_{\mathrm{a}}$ under the polymer voltammetric response following $\delta=2 Q_{\mathrm{a}} /\left(Q_{\mathrm{s}}-Q_{\mathrm{a}}\right)$ where $Q_{\mathrm{s}}$ is the electropolymerization charge. ${ }^{d}$ Position of the maximum absorption of the solid-state neutral polymer.

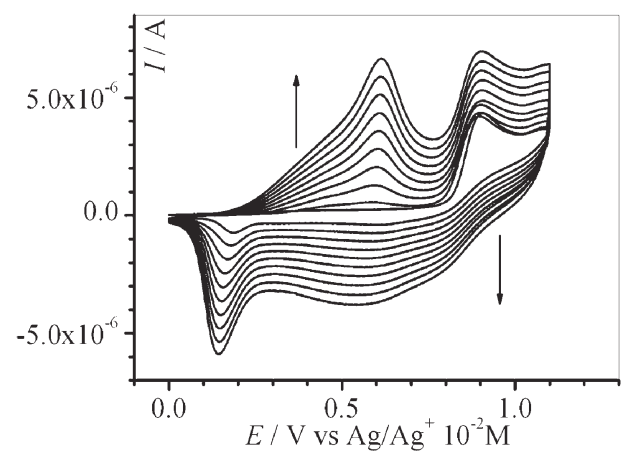

Fig. 2 Successive cyclic voltammograms at $0.1 \mathrm{~V} \mathrm{~s}^{-1}$ of 10 at $10 \mathrm{mM}$ in $\mathrm{CH}_{2} \mathrm{Cl}_{2}+0.2 \mathrm{M} \mathrm{Bu}_{4} \mathrm{NPF}_{6}$.

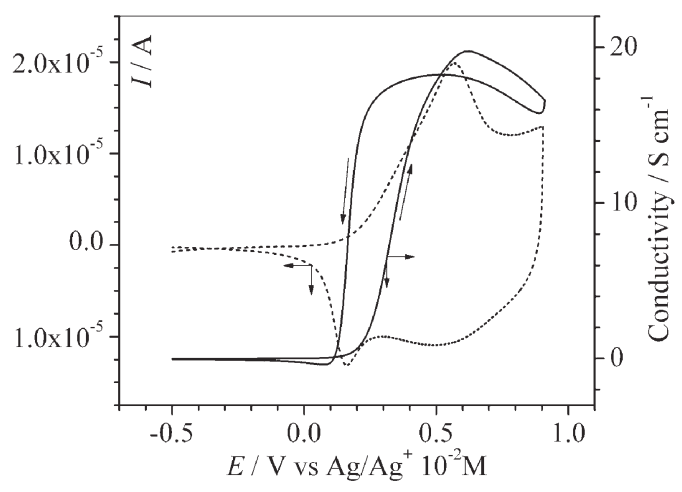

Fig. 3 Electrochemical response of poly(10) (dashed line) and conductivity $v$ s. potential (solid line) at $0.02 \mathrm{~V} \mathrm{~s}^{-1}$ in $\mathrm{CH}_{2} \mathrm{Cl}_{2}+0.2 \mathrm{M} \mathrm{Bu}_{4} \mathrm{NPF}_{6}$. band gap, and response for the high conductivity of polymers. ${ }^{18}$ Thus poly(10) is expected to be more conjugated and consequently more conducting than the other two related polymers (vide infra).

The above results were supported by the UV-visible spectroscopy analysis of the polymers in their neutral and p-doped forms (Fig. 4 and ESI:). In the neutral form, the three polymers display similar absorptions, with $c a .100 \mathrm{~nm}$ red shifts in the order poly(10) $>$ poly $(\mathbf{1 m})>$ poly $(\mathbf{1} \mathbf{p})$. Importantly, the neutral poly(10) shows a well-defined vibronic fine structure with maxima at 528, 565 and $615 \mathrm{~nm}$. Such optical features which are not observed for poly(1m) and poly(1p) are typical of highly conjugated, ordered polymers. ${ }^{19}$ A similar shifting is also observed for the oxidatively doped polymers that display a new longer wavelength band at 810,730 and $686 \mathrm{~nm}$ for poly(10), poly(1m) and poly(1p) respectively. All these differences indicate that the incorporation of $o$-carborane into the polymer backbone causes a more efficient reduction of the $\pi-\pi^{*}$ energy gap compared with the $m$ - and $p$-carboranes. For the three doped polymers, a further broad band attributed to the formation of the so-called "free carrier tail" 20 is also visible in the near IR region at $>1000 \mathrm{~nm}$.

In agreement with the UV-visible data, the in situ conductivity measurements of these polymers also show a clear dependency on the carborane isomer used. The conductivity profiles for poly $(\mathbf{1 m})$ and poly(1p) show maximum values of $\sim 12 \mathrm{~S} \mathrm{~cm}^{-1}$ at 0.9 and $1.2 \mathrm{~V}$ vs. $\mathrm{Ag} / \mathrm{Ag}^{+}$respectively. For poly(10), the conductivity reaches a quasi-plateau at much less positive potentials $(0.6 \mathrm{~V})$ with conductivities near $20 \mathrm{~S} \mathrm{~cm}^{-1}$ (Fig. 3). Furthermore, poly(10) showed high electrochemical stability and only a slight decrease in conductivity up to 1000 cycles. Again, the in situ conductivity data confirmed that the $o$-carborane cluster conferred the highest

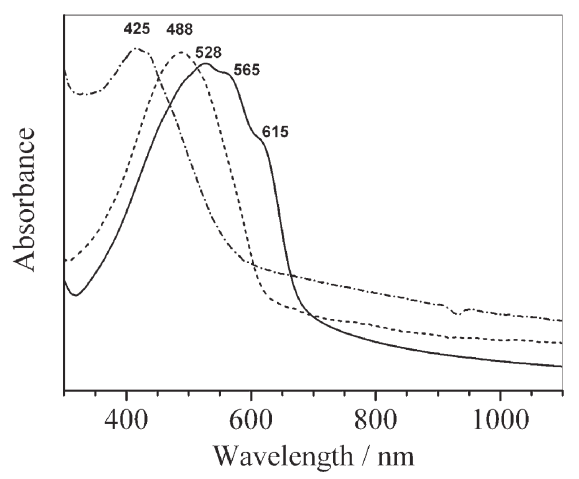

Fig. 4 Solid-state UV-visible spectra of undoped poly(1o) (solid line), poly(1m) (dashed line) and poly(1p) (dash-dotted line). 


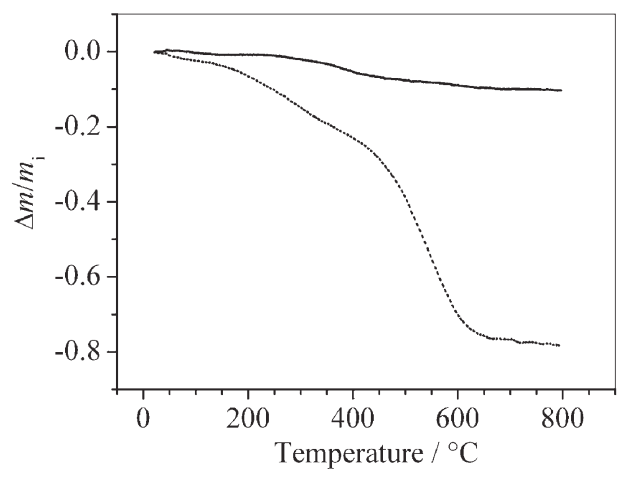

Fig. 5 TGA analysis of undoped poly(10) (solid line) and polythiophene (dashed line) under $\mathrm{N}_{2}$. Mass of polymer: $3 \mathrm{mg}$; heating rate: $10^{\circ} \mathrm{C} \mathrm{min}^{-1}$.

conductivity to the parent polymer of the three carborane isomers studied. The shape of the relationship of conductivity with potential suggested there was possibly mixed-valence conduction, as previously observed in polypyrrole, as a contribution to the bipolaron conduction. ${ }^{21}$ This would correspond to an equal concentration of polarons and bipolarons at the maximum conductivity.

The more conjugated and ordered structure of poly(10) compared with poly $(\mathbf{1 m})$ and poly(1p) could be explained by a more planar conformation of the conjugated backbone resulting from an intramolecular $\beta-\beta^{\prime}$ cyclization reaction in the monomer. Molecular modeling calculations using the DFT method are currently in progress to test this hypothesis.

The integration of carborane cages into the polymer backbone was also found to dramatically increase the thermal stability of the polymers. As an example, the thermogravimetric analysis (TGA) of undoped poly(10) is shown in Fig. 5. The TGA was performed under $\mathrm{N}_{2}$ up to $800{ }^{\circ} \mathrm{C}$. Compared with TGA of polythiophene, there is only a slight loss in the mass of poly(1o), less than $10 \%$ up to $800{ }^{\circ} \mathrm{C}$. For the parent polymer, there was a continuous loss in mass reaching $\sim 80 \%$ at $600{ }^{\circ} \mathrm{C}$.

In summary we report the preparation of new poly[di(2thiophenyl)carborane]s bearing either ortho-, meta- or paracarborane clusters. These materials show very high thermal and electrochemical stabilities in comparison with parent polythiophene. We show that the nature of the carborane groups strongly influences the conductivity of the resulting polymers. In particular the incorporation of $o$-carborane showed the greatest conductivity. Therefore a new design of conducting polymers with high electrochemical and thermal stabilities via the incorporation of $o$-carboranes into the conjugated polymer backbone has been developed.
The synthetic work described herein was supported by the National Institutes of Health (CA098902).

\section{Notes and references}

$\S$ Crystallographic data: 10 at $90 \mathrm{~K}: \mathrm{C}_{10} \mathrm{H}_{16} \mathrm{~B}_{10} \mathrm{~S}_{2}$, triclinic, space group $P \overline{1}$, $a=10.3905(12), b=12.330(2), c=12.5115(15) \AA, \alpha=81.871(7), \beta=$ 89.204(7), $\gamma=81.639(7)^{\circ}, V=1569.9(4) \AA^{3}, Z=4, D_{\mathrm{c}}=1.305 \mathrm{~g} \mathrm{~cm}^{-3}$, 40732 reflections collected with $\theta<30.9^{\circ}, 9669$ unique; $R 1=0.047, w R 2=$ 0.124 refined on $F^{2}, C C D C 650330 ; 1 \mathrm{~m}$ at $90 \mathrm{~K}: \mathrm{C}_{10} \mathrm{H}_{16} \mathrm{~B}_{10} \mathrm{~S}_{2}$, monoclinic, space group $C 2 / c, a=19.019(4), b=7.3765(10), c=13.170(3) \AA, \beta=$ $122.216(7)^{\circ}, V=1563.2(5) \AA^{3}, Z=4, D_{\mathrm{c}}=1.311 \mathrm{~g} \mathrm{~cm}^{-3}, 11174$ reflections collected with $\theta<32.9^{\circ}, 2865$ unique; $R 1=0.038, w R 2=0.103$, CCDC $650331 ; 1 p$ at $90 \mathrm{~K}: \mathrm{C}_{10} \mathrm{H}_{16} \mathrm{~B}_{10} \mathrm{~S}_{2}$, monoclinic, space group $P 2_{1} / c, a=$ 7.1753(10), $b=7.3908(10), c=15.103(2) \AA, \beta=102.266(6)^{\circ}, V=$ $782.65(18) \AA^{3}, Z=2, D_{\mathrm{c}}=1.309 \mathrm{~g} \mathrm{~cm}^{-3}, 17113$ reflections collected with $\theta<33.7^{\circ}, 3040$ unique; $R 1=0.039, w R 2=0.104$, CCDC 650332. For crystallographic data in CIF or other electronic format see DOI: 10.1039/ b710375a

1 G. Horowitz, Adv. Mater., 1998, 10, 365.

2 J. A. Letizia, A. Facchetti, C. L. Stern, M. A. Ratner and T. J. Marks, J. Am. Chem. Soc., 2005, 127, 13476.

$3 \mathrm{H}$. Li, A. Sundararaman, K. Venkatasubbaiah and F. Jäkle, J. Am. Chem. Soc., 2007, 129, 5792.

4 S. W. Thomas, III, G. D. Joly and T. M. Swager, Chem. Rev., 2007, 107, 1339 .

5 V. Savvateev, A. Yakimov and D. Davidov, Adv. Mater., 1999, 11, 519.

6 B. S. Ong, Y. Wu, P. Liu and S. Gardner, J. Am. Chem. Soc., 2004, 126, 3378.

7 M. Heeney, C. Bailey, K. Genevicius, M. Shkunov, D. Sparrowe, S. Tierney and I. McCulloch, J. Am. Chem. Soc., 2005, 127, 1078.

8 K. Sivula, C. K. Luscombe, B. C. Thompson and J. M. J. Fréchet, J. Am. Chem. Soc., 2006, 128, 13988.

9 D. Lee and T. M. Swager, J. Am. Chem. Soc., 2003, 125, 6870.

10 P. F. H. Schwab, M. D. Levin and J. Michl, Chem. Rev., 1999, 99, 1863.

11 H. M. Colquhoun, P. L. Herbertson, K. Wade, I. Baxter and D. J. Williams, Macromolecules, 1998, 31, 1694.

12 U. Schöberl, T. F. Magnera, R. M. Harrison, F. Fleischer, J. L. Pflug, P. F. H. Schwab, X. Meng, D. Lipiak, B. C. Noll, V. S. Allured, T. Rudalevige, S. Lee and J. Michl, J. Am. Chem. Soc., 1997, 119, 3907.

13 C. Masalles, S. Borrós, C. Viñas and F. Teixidor, Adv. Mater., 2000, 12, 1199.

14 C. Masalles, S. Borrós, C. Viñas and F. Teixidor, Adv. Mater., 2002, 14, 449.

15 B. Fabre, S. Chayer and M. G. H. Vicente, Electrochem. Commun., $2003,5,431$.

16 B. Fabre, J. C. Clark and M. G. H. Vicente, Macromolecules, 2006, 39, 112.

17 R. Coult, M. A. Fox, W. R. Gill, P. L. Herbertson, J. A. H. MacBride and K. Wade, J. Organomet. Chem., 1993, 462, 19.

18 G. Zotti, R. Salmaso, M. C. Gallazzi and R. A. Marin, Chem. Mater., 1997, 9, 791.

19 J. Roncali, Chem. Rev., 1997, 97, 173.

20 G. G. Wallace, G. M. Spinks, L. A. P. Kane-Maguire and P. R. Teasdale, Conductive Electroactive Polymers, CRC Press. LLC, Boca Baton, London, New York, Washington, D. C., 2nd edn, 2003.

21 G. Zotti and G. Schiavon, Chem. Mater., 1991, 3, 62. 